\title{
Impaired fasting glucose (IFG)
}

National Diabetes Information Clearinghouse (NDIC)

\section{Definitions}

Fasting blood glucose test

Defined by National Diabetes Information Clearinghouse (NDIC)

Glucose

Defined by National Diabetes Information Clearinghouse (NDIC)

\section{Diabetes}

Defined by National Diabetes Information Clearinghouse (NDIC)

Pre-diabetes

Defined by National Diabetes Information Clearinghouse (NDIC)

$\mathrm{mg} / \mathrm{dL}$

Defined by National Diabetes Information Clearinghouse (NDIC)

Type 2 diabetes

Defined by National Diabetes Information Clearinghouse (NDIC)

Stroke

Defined by National Diabetes Information Clearinghouse (NDIC)

\section{Source}

National Diabetes Information Clearinghouse (U.S.). (2009). The diabetes dictionary. [Bethesda, Md.]: U.S. Dept. of Health and Human Services, National Institutes of Health, National Institute of Diabetes and Digestive and Kidney Diseases, National Diabetes Information Clearinghouse.

A condition in which a fasting blood glucose test shows a level of glucose higher than normal but not high enough for a diagnosis of diabetes. IFG, also called pre-diabetes, is a level of 100 to $125 \mathrm{mg} / \mathrm{dL}$. People with pre-diabetes are at increased risk for developing type 2 diabetes, heart disease, and stroke. 